\title{
CHANGES IN ENDOTHELIAL CELL COUNT AND CENTRAL CORNEAL THICKNESS IN MANUAL SMALL INCISION CATARACT SURGERY VERSUS PHACOEMULSIFICATION CATARACT SURGERY
}

\author{
Reni Philip1, Jisha Kamalakshy², Vijayamma Narayaniyamma³
}

${ }^{1}$ Senior Resident, Department of Ophthalmology, Government Medical College, Kottayam.

${ }^{2}$ Associate Professor, Department of Ophthalmology, Government Medical College, Kottayam.

3Professor, Department of Ophthalmology, Government Medical College, Kottayam.

\section{ABSTRACT \\ CONTEXT \\ The corneal endothelial cells are incapable of regeneration. When the endothelial cell density falls below 500 cells $/ \mathrm{mm}^{2}$, corneal decompensation occurs resulting in corneal oedema. Manual Small Incision Cataract Surgery (SICS) and phacoemulsification are two common techniques of cataract surgery followed.}

\section{AIM}

To study the relationship between change in corneal endothelial cell density and the change in central corneal thickness before and after surgery in manual small incision cataract surgery versus phacoemulsification cataract surgery.

\section{SETTINGS AND DESIGN}

Department of Ophthalmology, Govt. Medical College, Kottayam. Longitudinal study.

\section{MATERIALS AND METHODS}

Subjects selected were patients admitted for cataract surgery (Manual small incision cataract surgery and phacoemulsification cataract surgery). The basic details of the patients and type of surgery going to be done were obtained. The endothelial cell count and central corneal thickness was measured (Using SP3000 P, TOPCON specular microscope with pachymeter on 3 occasions - 1 day prior to surgery, one day after surgery and 4 weeks after surgery. The collected data was entered in excel and analysed using SPSS 16.0. The percentage decrease in endothelial cell count and increase in corneal thickness was calculated and compared among the two groups. Statistical analysis used, $t$ test.

\section{RESULTS}

Average CCT of SICS and phaco group was comparable on postoperative day 1 (SICS - $555.1 \mu$ phaco - $564.71 \mu$ ), day 7 (SICS $535.08 \mu$, phaco - $539.43 \mu$ ), day 28 (SICS-520.04 $\mu$, phaco - $523.49 \mu$ ). Percentage loss of endothelial cells - 6.78\% in SICS and 5.49\% in phacoemulsification on postoperative day 28.

\section{CONCLUSIONS}

There is no statistical significance in the decrease in endothelial cell count or increase in CCT between SICS and phacoemulsification.

\section{KEYWORDS}

Endothelial Cell Count, Central Corneal Thickness, Small Incision Cataract Surgery, Phacoemulsification.

HOW TO CITE THIS ARTICLE: Philip R, Kamalakshy J, Narayaniyamma V. Changes in endothelial cell count and central corneal thickness in manual small incision cataract surgery versus phacoemulsification cataract surgery. J. Evolution Med. Dent. Sci. 2016;5 (43):2679-2686, DOI: $10.14260 /$ jemds/2016/627

\section{INTRODUCTION}

More than $80 \%$ of our information from the external world is obtained by our visual function. ${ }^{1}$ The transparency of cornea is essential to ensure a clear image on the retina.

After endothelial damage surrounding cells are not capable of regeneration leading to a fall in cell density, which if less than critical level $\left(500\right.$ cells $\left./ \mathrm{mm}^{2}\right) .^{2}$ results in corneal decompensation with corneal oedema and loss of transparency.

Central thickness of cornea is approximately $520 \mu$, which increases after damage to endothelial cells. ${ }^{3}$ Variable

Financial or Other, Competing Interest: None.

Submission 16-04-2016, Peer Review 10-05-2016,

Acceptance 16-05-2016, Published 28-05-2016.

Corresponding Author:

Dr. Reni Philip,

Gauthama,

Railway Station Road,

Pettah,

Trivandrum-695024.

E-mail:dr.reniphilip@yahoo.in

DOI: $10.14260 /$ jemds $/ 2016 / 627$ endothelial cell loss occurs during cataract surgery depending on the technique used, instrumentation, use of protective viscoelastic material and the irrigating solution used. ${ }^{4}$ Manual Small Incision Cataract Surgery (SICS) and phacoemulsification are two techniques of cataract surgery presently followed. This study aims to determine as to which technique will maintain the corneal parameters closest to the normal physiological state.

\section{AIM}

1. To study the relationship between change in corneal endothelial cell density before and after surgery in manual small incision cataract surgery versus phacoemulsification cataract surgery in patients undergoing cataract surgery in our centre.

2. To study the change in central corneal thickness before and after manual small incision cataract surgery and phacoemulsification surgery in the same population.

\section{SUBJECTS AND METHODS}

Study Design

Longitudinal study. 


\section{Duration of Study}

One year from January 2013 to January 2014.

\section{Sample Size}

A total of 120 patients were studied; 60 patients who had undergone manual SICS and 60 patients who had undergone phacoemulsification cataract surgery.

\section{Study Tools}

SP3000 P, TOPCON specular microscope with pachymeter; questionnaire.

\section{Study Procedure}

Subjects selected were patients admitted for cataract surgery (Manual small incision cataract surgery and phacoemulsification cataract surgery) during the study period who satisfied the inclusion criteria and had given consent to participate in the study.

The basic details of the patients and type of surgery going to be done were obtained. The endothelial cell count and central corneal thickness was measured (Using SP3000 P, TOPCON specular microscope with pachymeter on 3 occasions - 1 day prior to surgery, one day after surgery and 4 weeks after surgery. Manual SICS and phacoemulsification was done by same senior surgeons, who are well versed in both the techniques.

Manual SICS was done through superior section. Nucleus delivery was done using irrigating wire vectis and rigid intraocular lens implanted. Phacoemulsification surgery was done through superior limbal $3 \mathrm{~mm}$ incision and nucleus removed by divide and conquer technique and foldable intraocular lens implanted. During surgery the two groups (Manual SICS and phacoemulsification) were operated using same viscoelastic material to avoid difference in endothelial cell count change due to protective effect on endothelium of viscoelastic substance. The collected data was entered in excel and analysed using SPSS 16.0. The percentage decrease in endothelial cell count and increase in corneal thickness was calculated. The decrease in endothelial cell count and increase in corneal thickness was compared using t test.

\section{Inclusion Criteria}

Patients between 45 and 75 yrs. of age having immature senile cataract admitted in our hospital during the study period for small incision cataract surgery and phacoemulsification cataract surgery.

\section{Exclusion Criteria}

Patients who had not given consent.

Patients with mature cataract or hypermature cataract.

Patients with nuclear sclerosis grade 4 .

Patients with traumatic cataract.

Patients with glaucoma.

Patients with other corneal diseases.

Patients with other ocular surgeries or ocular trauma in the past in the concerned eye.

Patients with intraoperative complications during cataract surgery.

\section{RESULTS}

\section{Pre-operative Distribution of Endothelial Cell Count and} CCT

The preoperative Endothelial Cell Count (EC) in the study group that underwent SICS had a minimum endothelial cell count of $1871 / \mathrm{mm}^{2}$ and a maximum count of $3023 / \mathrm{mm}^{2}$. In the phacoemulsification group, the endothelial cell counts ranged between a minimum of 1840 cells $/ \mathrm{mm}^{2}$ and a maximum count of 3225 cells $/ \mathrm{mm}^{2}$. The mean endothelial cell count preoperatively was 2363.02 in the SICS group and 2329.92 in the phaco group (Fig. 1, 2).

The preoperative Central Corneal Thickness (CCT) varied between $443 \mu$ to $568 \mu$ in the SICS group with a mean of $503.62 \mu$, whereas in the phacoemulsification group the minimum CCT was $434 \mu$ and a maximum was $581 \mu$ and the mean was $508.72 \mu$ (Fig. 3, 4).

The preoperative details regarding the endothelial cell count and central corneal thickness are summarised in the Table 1. On doing a t-test, there was no statistically significant difference in the distribution of the endothelial cell count and central corneal thickness in the two groups (Table 1).

\section{Analysis of Post-Operative Endothelial Cell Count and Central Corneal Thickness}

Post-operatively, the group wise mean endothelial cell count and central corneal thickness on days 1, 7 and 28 was calculated. The difference of post-operative values from preoperative values in endothelial cell count and central corneal thickness (which occurred as a result of the cataract surgery) was also calculated. Analysis of intergroup difference in post-operative endothelial cell count, post-operative endothelial cell count change, post-operative central corneal thickness and post-operative change in central corneal thickness was done by calculating the mean, standard deviation and the statistical significance calculated using the $t$ test.

\section{The Results are as follows on Post-operative Day 1}

The mean CCT in SICS patients was $555.1 \mu$ and the mean in the phacoemulsification group was $564.71 \mu$.

The change in CCT ranged between a minimum difference of $7 \mu$ to a maximum difference of $117 \mu$ in the SICS group. In the phacoemulsification group, the minimum CCT change was $5 \mu$ and the maximum change in CCT was $134 \mu$ (Fig. 5, 6).

In the SICS group the mean increase in CCT on postoperative day 1 was $50.47 \mu$ with a standard deviation of 25.087, whereas in the phacoemulsification group the mean increase was $55.98 \mu$ on the first postoperative day when compared to the preoperative CCT with a standard deviation of 25.399 (Table 2).

The percentage increase in CCT was $10.02 \%$ in the SICS group and $11.00 \%$ in the phacoemulsification group.

On statistical analysis using independent t-test, there was no significant difference for change in CCT in the first postoperative day $(p=0.240)$ between the two groups. However, there was a statistically significant difference between preoperative CCT and post-operative CCT on post-operative days 1,7 and 28 in both the groups $(\mathrm{p}<0.0001)$.

In the SICS group the mean EC on the first post-operative day was 2272.29 cells $/ \mathrm{mm}^{2}$ and in the phacoemulsification group it was 2240.92 cells $/ \mathrm{mm}^{2}$.

In the SICS group, the minimum decrease in endothelial cell count on the first postoperative day was 2 cells $/ \mathrm{mm}^{2}$ and the maximum cell count decrease was 302 cells $/ \mathrm{mm}^{2}$. In the phacoemulsification group, the minimum endothelial cell count decrease on the first postoperative day was 6 cells $/ \mathrm{mm}^{2}$ 
and the maximum decrease in endothelial cell count was 320 cells/mm² (Fig. 7, 8).

The mean change in the endothelial cell count on the first post-operative day in the SICS group was 94.36 cells $/ \mathrm{mm}^{2}$ with a standard deviation of 65.625 . The mean decrease in the phacoemulsification group was 80.59 cells $/ \mathrm{mm}^{2}$ with a standard deviation of 68.267 (Table 3).

The percentage decrease in the endothelial cell density was $3.9 \%$ in the SICS group and $3.46 \%$ in the phacoemulsification group. On statistical analysis using the paired t-test, no statistically significant difference was found for the change in endothelial cell count on the first postoperative day $(\mathrm{p}=0.269)$ between the two groups.

\section{Post-operative Day 7}

The mean CCT in the SICS group was $535.08 \mu$ and in the phacoemulsification group was $539.43 \mu$. In the SICS group, the increase in CCT on the seventh postoperative day varied from a minimum of $2 \mu$ to a maximum of $83 \mu$. In the phacoemulsification group, it varied from a minimum of $2 \mu$ to a maximum of $69 \mu$ (Fig. 9, 10). The SICS group showed a mean CCT increase of $30.32 \mu$ with a standard deviation of 17.808 , whereas the phacoemulsification group had an average CCT increase of $30.36 \mu$. The standard deviation was 17.941 (Table 4).

The percentage increase in CCT was $6.02 \%$ in the SICS group and $5.97 \%$ in the phacoemulsification group. Statistical analysis using the paired t-test showed no statistically significant difference in the increase in CCT between the two groups $(\mathrm{p}=0.992)$. The mean EC on the seventh postoperative day in the SICS group was 2213.86 cells $/ \mathrm{mm}^{2}$ and in the phacoemulsification group it was 2184.25 cells $/ \mathrm{mm}^{2}$. The endothelial cell density decrease varied from a minimum of 14 cells $/ \mathrm{mm}^{2}$ to a maximum of 543 cells $/ \mathrm{mm}^{2}$ in the SICS group, and from 12 cells $/ \mathrm{mm}^{2}$ to 455 cells $/ \mathrm{mm}^{2}$ in the phacoemulsification group (Fig. 11, 12).

The mean decrease in endothelial cell density was 142.20 cells $/ \mathrm{mm}^{2}$ in the SICS group with a standard deviation of 105.054 cells $/ \mathrm{mm}^{2}$. In the phacoemulsification group, the mean decrease in endothelial cell density was 134.77 cells $/ \mathrm{mm}^{2}$ with a standard deviation of 112.512 (Table 5).

The percentage decrease in EC was $6.01 \%$ in the SICS group and $4.51 \%$ in the phacoemulsification group (Table 5). Statistical testing for significance in difference in the endothelial cell density change on the seventh postoperative day between the SICS and phacoemulsification patients showed no significant difference between the two groups $(\mathrm{p}=0.727)$.

\section{Post-operative Day 28}

The mean CCT in SICS patients was $520.05 \mu$ and in phacoemulsification patients was $523.49 \mu$. The increase in CCT in the SICS group ranged between a minimum of $1 \mu$ to a maximum of $48 \mu$, whereas in the phacoemulsification group it ranged between a minimum of $2 \mu$ to a maximum of $52 \mu$ (Fig. 13, 14).

The mean increase in CCT in the SICS group was $13.88 \mu$ (Standard deviation=11.238) and in the phacoemulsification group was $14.43 \mu$ (Standard deviation=15.911) (Table 6).

The percentage increase in CCT was $2.76 \%$ in the SICS group and $2.84 \%$ in the phacoemulsification group. There was no statistically significant difference between the change in CCT on the $28^{\text {th }}$ post-operative day between the two groups (Tested using t-test, $\mathrm{p}=0.854$ ). The mean EC in SICS patients was 2213.93 cells $/ \mathrm{mm}^{2}$ and in phacoemulsification patients it was 2181.74 cells $/ \mathrm{mm}^{2}$.

The decrease in EC on post-operative day 28 in SICS ranged between 56 cells $/ \mathrm{mm}^{2}$ to 407 cells $/ \mathrm{mm}^{2}$ and in the phacoemulsification group it ranged between 18 cells $/ \mathrm{mm}^{2}$ to 589 cells $/ \mathrm{mm}^{2}$ (Fig. 15, 16). The average decrease in endothelial cell density was 160.34 cells $/ \mathrm{mm}^{2}$ in the SICS group (Standard deviation=99.089) and 127.96 cells $/ \mathrm{mm}^{2}$ in the phacoemulsification group (Standard deviation=108.084) (Table 7).

The percentage decrease in EC was $6.78 \%$ in the SICS group and $5.49 \%$ in the phacoemulsification group. There was no statistically significant difference between the change in EC on the $28^{\text {th }}$ postoperative day between the two groups (Tested using t-test, $\mathrm{p}=0.135$ ).

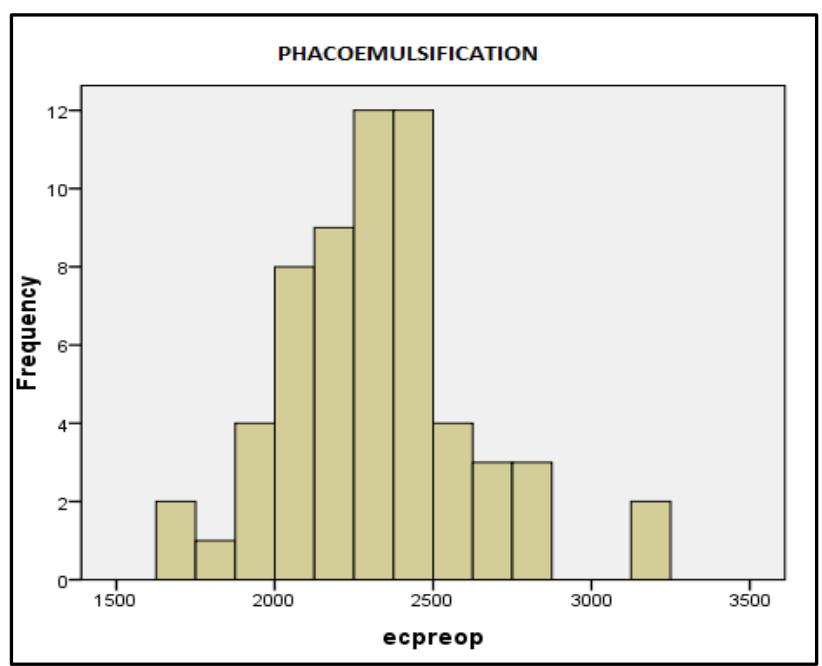

Fig. 1, 2: Preoperative EC in SICS and Phaco 

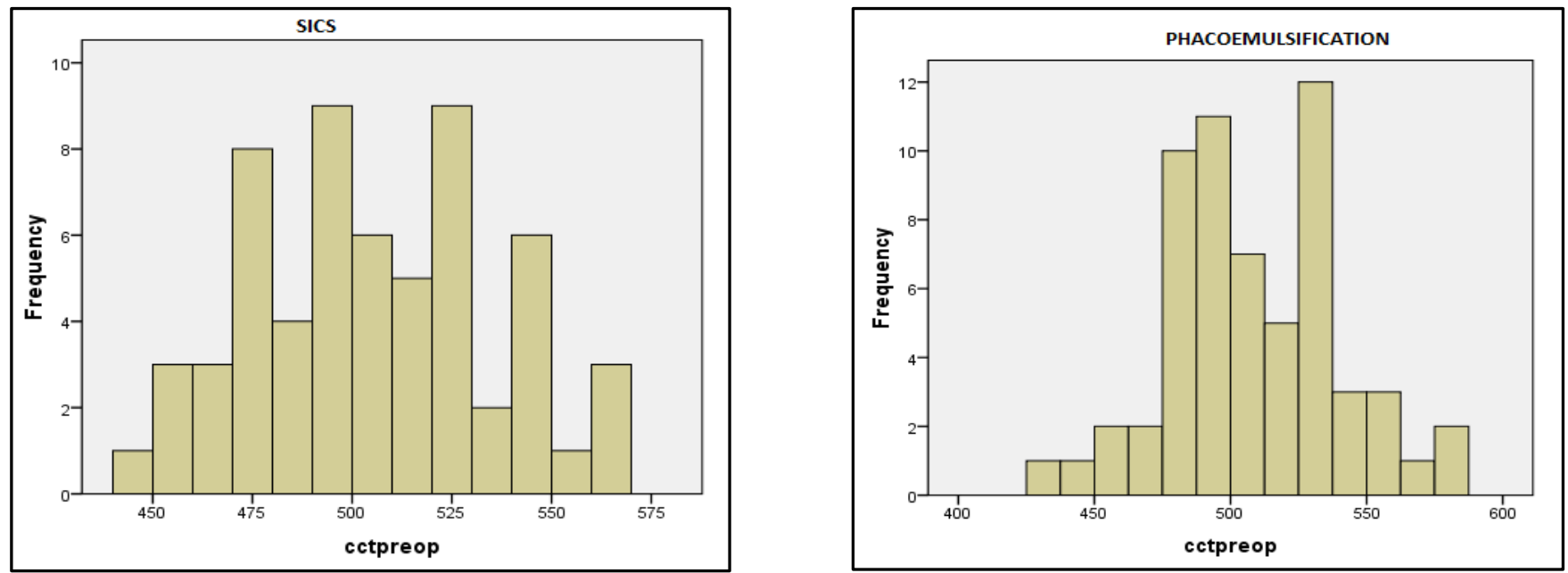

Fig. 3, 4: Preoperative CCT in SICS and Phaco

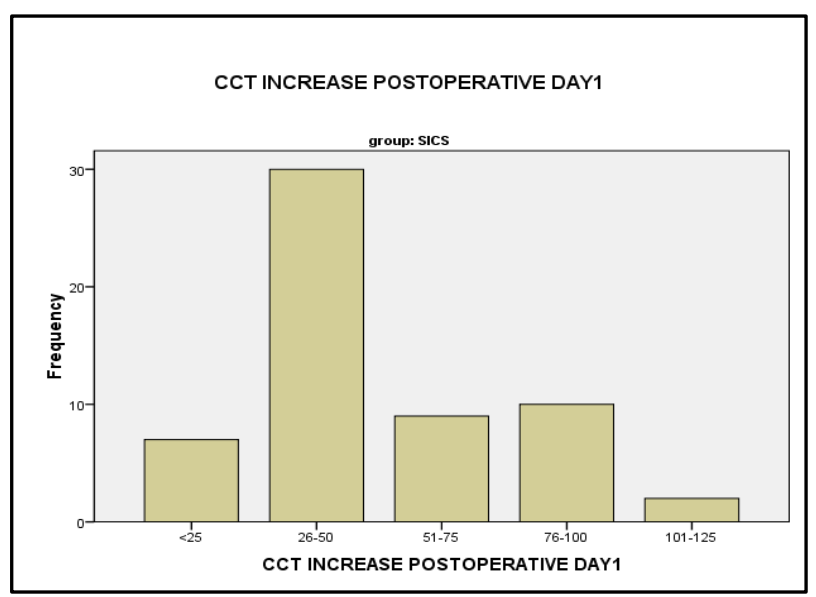

Fig. 5: Increase in CCT after SICS on First Postoperative Day

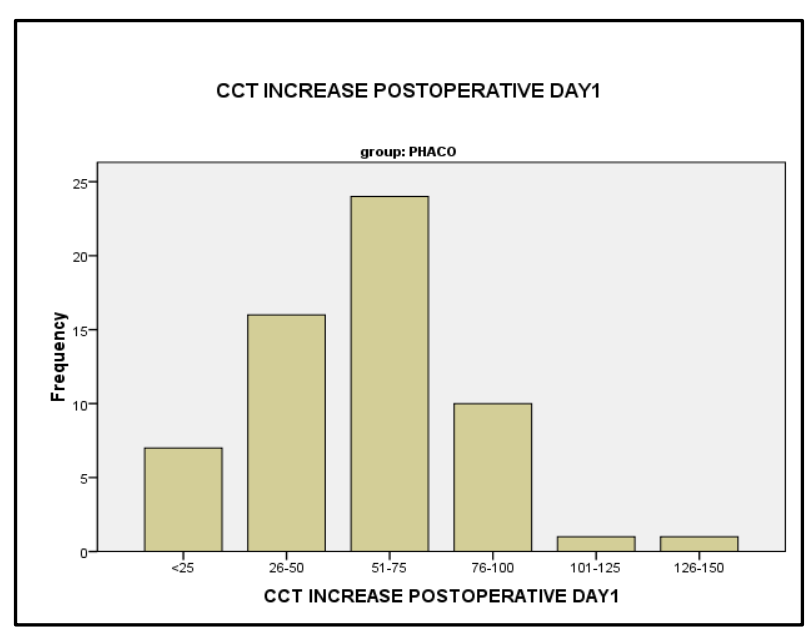

Fig. 6: Increase in CCT after Phacoemulsification on First Postoperative Day

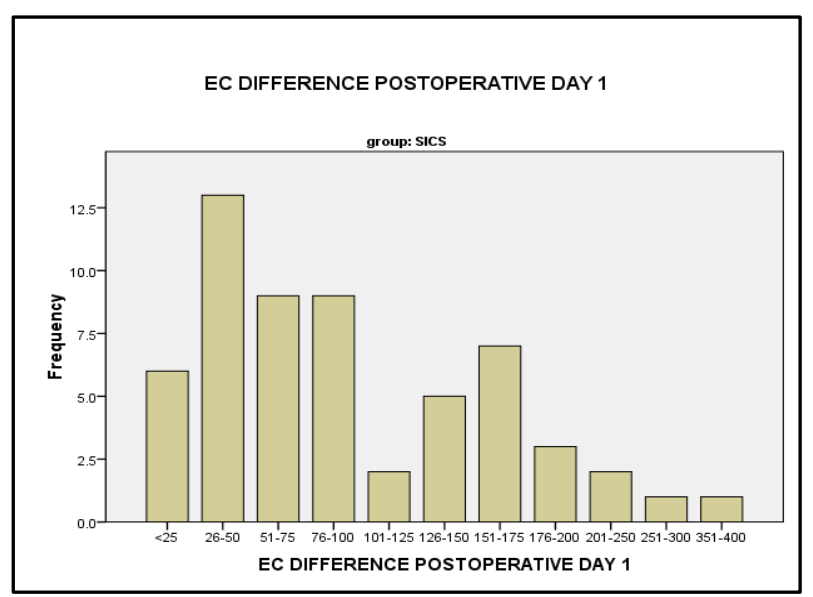

Fig. 7: Decrease in Endothelial Cell Count on the First Postoperative Day after SICS

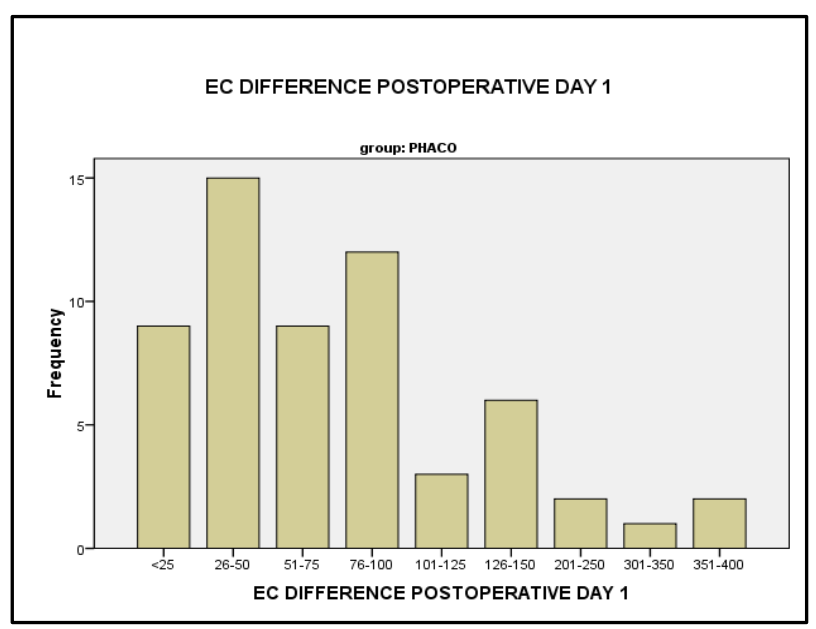

Fig. 8: Decrease in Endothelial Cell Count on the First Postoperative Day after Phacoemulsification 


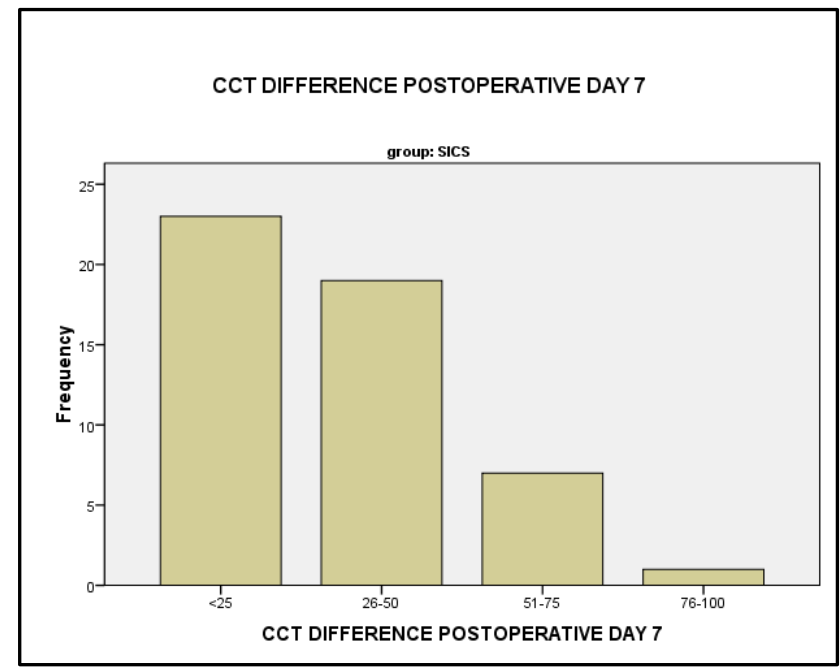

Fig. 9: Increase in CCT after SICS, Postoperative Day 7

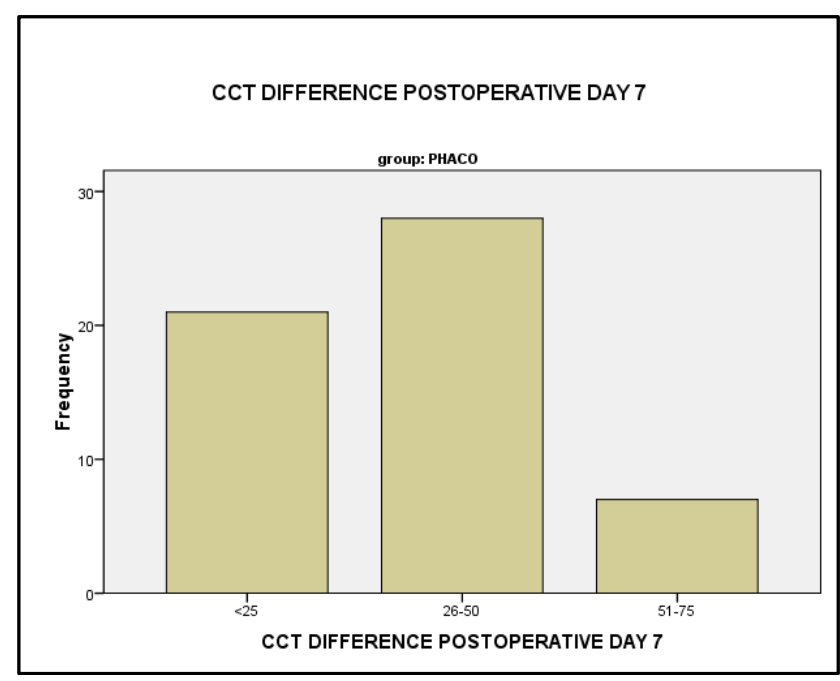

Fig. 10: Increase in CCT after Phaco, Postoperative Day 7

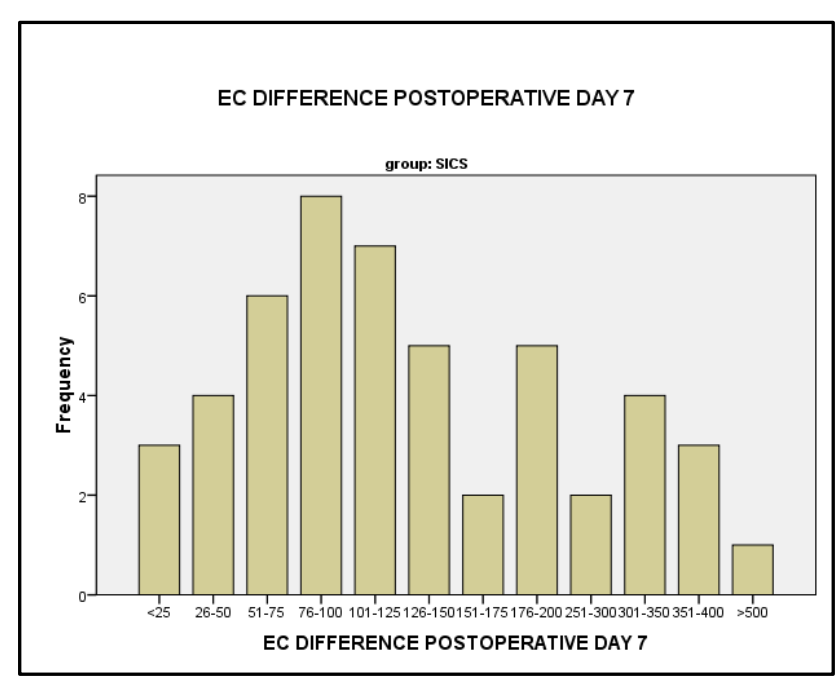

Fig. 11: Decrease in Endothelial Cell Count after SICS, Postoperative Day 7

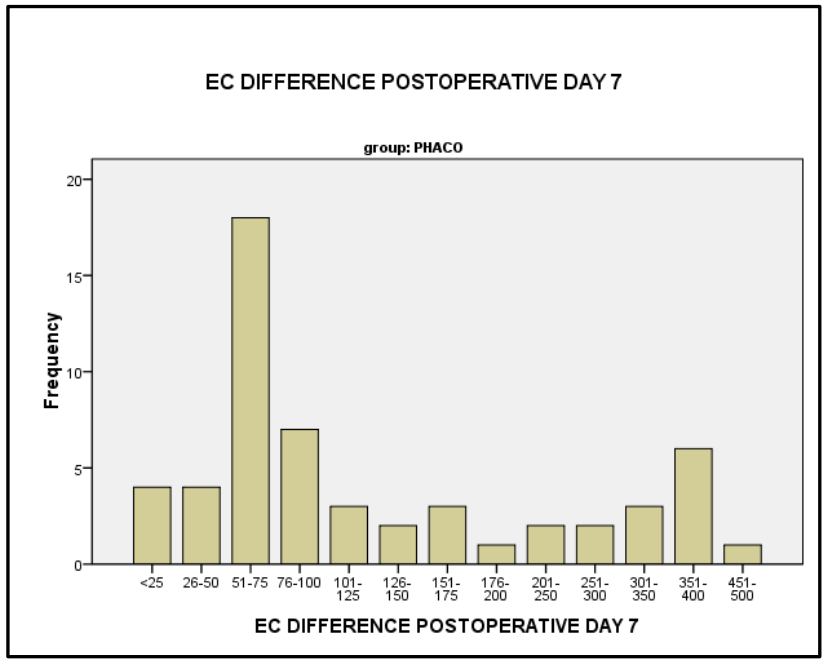

Fig. 12: Decrease in Endothelial Cell Count after Phacoemulsification, Postoperative Day 7

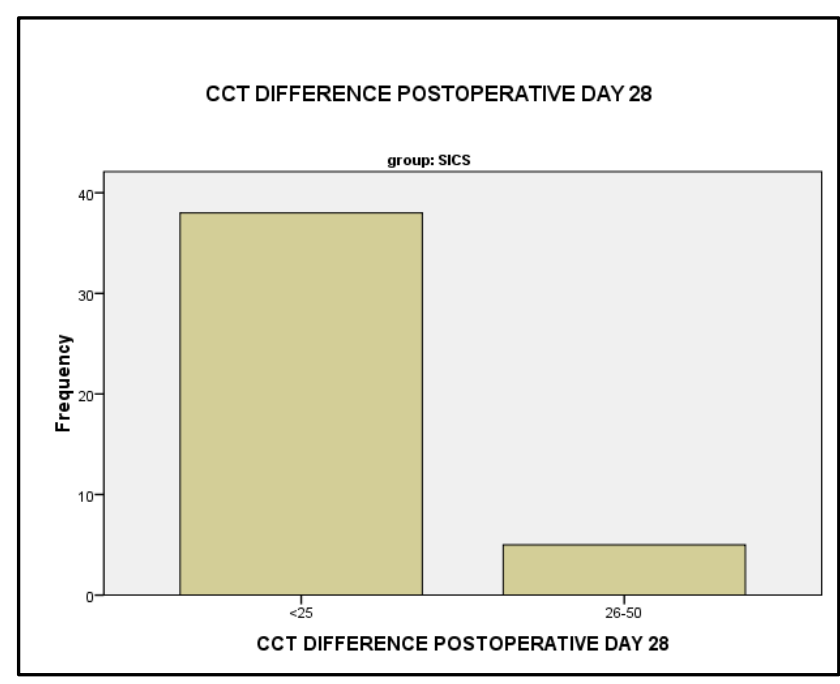

Fig. 13: Increase in CCT after SICS, Postoperative Day 28

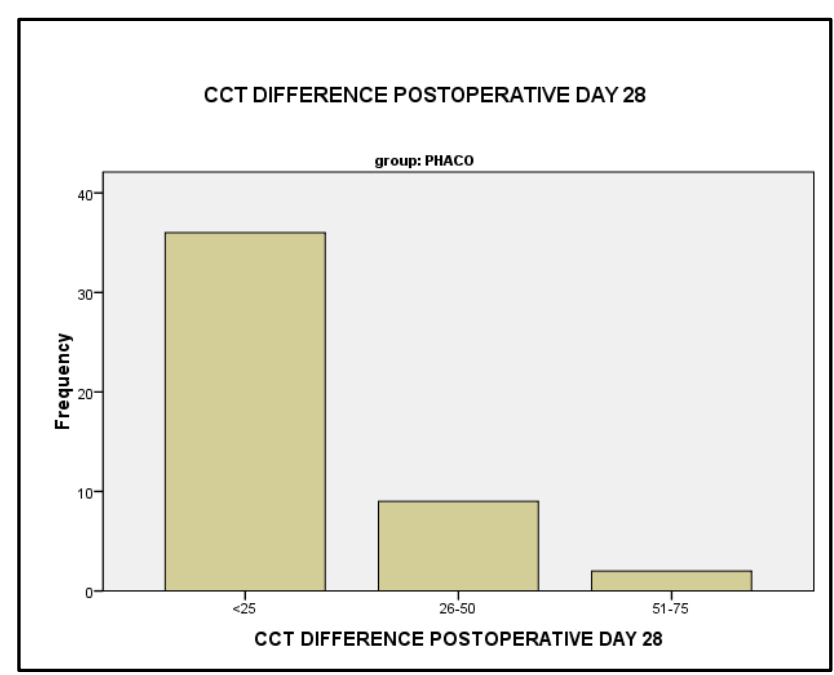

Fig. 14: Increase in CCT after Phacoemulsification, Postoperative Day 28 


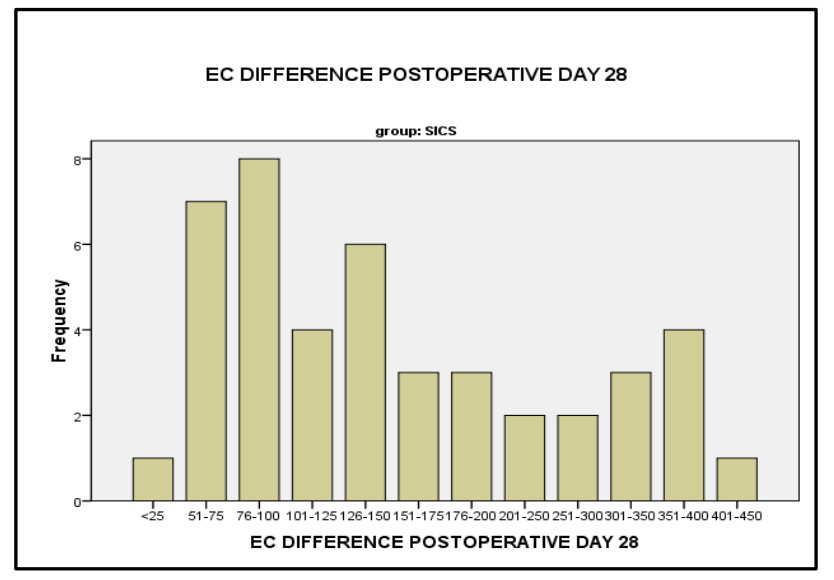

Fig. 15: Decrease in Endothelial Cell Count after SICS, Postoperative Day 28

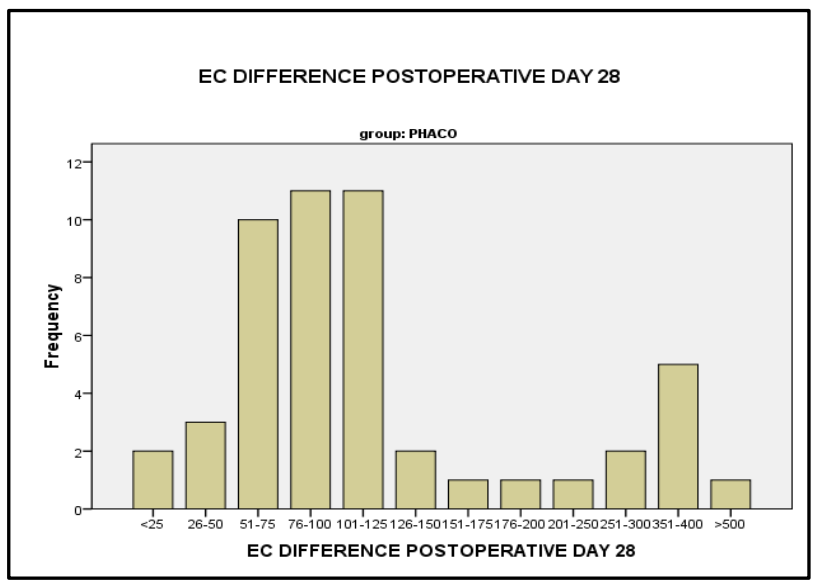

Fig. 16: Decrease in Endothelial Cell Count after Phacoemulsification, Postoperative Day 28

\begin{tabular}{|c|c|c|c|c|c|c|}
\hline \multicolumn{7}{|c|}{ Preoperative Values } \\
\hline & \multicolumn{3}{|c|}{ SICS } & \multicolumn{3}{|c|}{ Phacoemulsification } \\
\hline & Minimum & Maximum & Mean & Minimum & Maximum & Mean \\
\hline CCT $(\mu)$ & 443 & 568 & 503.62 & 434 & 581 & 508.72 \\
\hline EC (Cells/mm2) & 1871 & 3023 & 2363.02 & 1840 & 3225 & 2329.9 \\
\hline \multicolumn{7}{|c|}{ Table 1: Summary of Preoperative CCT and EC in SICS and Phaco } \\
\hline
\end{tabular}

\begin{tabular}{|c|c|c|c|c|}
\hline & \multicolumn{3}{|c|}{ Change in CCT on Postoperative Day 1} & \\
\hline Technique & Minimum & Maximum & Mean & Standard Deviation \\
\hline SICS & $7 \mu$ & $117 \mu$ & $50.47 \mu$ & 25.087 \\
\hline PHACO & $5 \mu$ & $134 \mu$ & $55.98 \mu$ & 25.399 \\
\hline
\end{tabular}

\begin{tabular}{|c|c|c|c|c|}
\hline & \multicolumn{3}{|c|}{ Change in EC on Postoperative Day 1} & \\
\hline Technique & Minimum & Maximum & Mean & Standard Deviation \\
\hline SICS & 2 cells $/ \mathrm{mm}^{2}$ & 302 cells $/ \mathrm{mm}^{2}$ & 94.36 cells $/ \mathrm{mm}^{2}$ & 65.625 \\
\hline PHACO & 6 cells $/ \mathrm{mm}^{2}$ & 320 cells $/ \mathrm{mm}^{2}$ & 80.59 cells $/ \mathrm{mm}^{2}$ & 68.267 \\
\hline
\end{tabular}

\begin{tabular}{|c|c|c|c|c|}
\hline & \multicolumn{3}{|c|}{ Change in CCT on Postoperative Day 7 } & Mean \\
\hline Technique & Minimum & Maximum & $30.32 \mu$ & 17.808 \\
\hline SICS & $2 \mu$ & $83 \mu$ & $30.36 \mu$ & 17.941 \\
\hline Phaco & $2 \mu$ & $69 \mu$ & Table 4: Change in CCT on Postoperative Day 7 in SICS vs Phacoemulsification \\
\hline
\end{tabular}

\begin{tabular}{|c|c|c|c|c|}
\hline & \multicolumn{3}{|c|}{ Change in EC on Postoperative Day 7 } & Standard Deviation \\
\hline Technique & Minimum & Maximum & $142.20 \mathrm{cells} / \mathrm{mm}^{2}$ & 105.054 \\
\hline SICS & 14 cells $/ \mathrm{mm}^{2}$ & $543 \mathrm{cells} / \mathrm{mm}^{2}$ & 134.77 cells $/ \mathrm{mm}^{2}$ & 112.512 \\
\hline PHACO & 12 cells $/ \mathrm{mm}^{2}$ & 455 cells $/ \mathrm{mm}^{2}$ & 13 . & Table 5: Change in EC on Postoperative Day 7 in SICS vs Phacoemulsification \\
\hline
\end{tabular}

\begin{tabular}{|c|c|c|c|c|}
\hline & \multicolumn{3}{|c|}{ Change in CCT on Postoperative Day 28 } & Mean \\
\hline Technique & Minimum & Maximum & $13.88 \mu$ & 11.238 \\
\hline SICS & $1 \mu$ & $48 \mu$ & $14.43 \mu$ & 15.911 \\
\hline PHACO & $2 \mu$ & $52 \mu$ & \multicolumn{2}{c|}{} \\
\hline \multicolumn{4}{|r}{ Table 6: Change in CCT on Postoperative Day 28 in SICS vs Phacoemulsification } \\
\hline
\end{tabular}

\begin{tabular}{|c|c|c|c|c|}
\hline & \multicolumn{3}{|c|}{ Change in EC on Postoperative Day 28 } & Mean \\
\hline Technique & Minimum & Maximum & Standard Deviation \\
\hline SICS & 56 cells $/ \mathrm{mm}^{2}$ & 407 cells $/ \mathrm{mm}^{2}$ & 160.34 cells $/ \mathrm{mm}^{2}$ & 99.089 \\
\hline PHACO & 18 cells $/ \mathrm{mm}^{2}$ & 589 cells $/ \mathrm{mm}^{2}$ & 127.96 cells $/ \mathrm{mm}^{2}$ & 108.084 \\
\hline \multicolumn{4}{|r}{} \\
\hline
\end{tabular}




\section{DISCUSSION}

\section{Central Corneal Thickness}

The average CCT of the SICS and phaco group was comparable preoperatively (SICS - $503.62 \mu$, phaco - $508.72 \mu$ ) and on postoperative day 1 (SICS - $555.1 \mu$ phaco $-564.71 \mu$ ), day 7 (SICS $535.08 \mu$, phaco $-539.43 \mu$ ) and day 28 (SICS - $520.04 \mu$, phaco $-523.49 \mu$ ).

There is a significant increase in the CCT when analysing pre- and post-cataract surgery CCT with a maximum increase in CCT on post-op day $1(\mathrm{p}<0.0001)$. The CCT shows a decreasing trend over days 7 and 21 , but remains significantly increased.

There is no significant difference in change in CCT between the two groups with respect to increase in CCT postoperatively on days 1, 7 and 28. A study by Goldenberg D et al in 2013.5 showed similar results with significant increase in CCT post manual small incision cataract surgery when compared to preoperative values on first post-operative week and first month post-operatively. The study also showed a return to normal values by third month.

A study by Amon M et al in 1991 and 1992.6,7 showed a return of the CCT to normal thickness one month postoperatively after phacoemulsification. A study by Mathew PT et al in 2011. ${ }^{8}$ showed an increasing trend in CCT after SICS for the first two weeks followed by a decrease in the thickness.

\section{Endothelial Cell Count}

The average endothelial cell count was also comparable between the SICS and phaco groups. The percentage of loss of endothelial cells were found to be $6.78 \%$ in SICS and 5.49\% in phacoemulsification on post-operative day 28 . No statistically significant difference was obtained in the decrease in endothelial cell counts between the two groups.

The average endothelial cell count in the study population is within the normal range of $2000-3000$ cells $/ \mathrm{mm}^{2}$. The percentage endothelial cell loss (SICS - 6.78\%, phaco 5.49\%) is similar to the value for cell loss in phaco and slightly more than the value for cell loss in SICS obtained by George $\mathrm{R}$ et al in $2005 .{ }^{9}$ (SICS - $4.21 \%$, phaco - $5.41 \%$ ).

No significant cell loss was found between the phaco group and SICS group in this study also, which is similar to the result by George R et al.

The percentage endothelial cell loss for SICS was however much lesser than the values obtained by Thakur SK et al in $2011 .{ }^{10}(15.83 \%)$. The values of endothelial cell loss at $6 \mathrm{wks}$. by Gogate $\mathrm{P}$ et al in $2010 .{ }^{11}$ were much higher (SICS-15.52\%, phaco-15.33\%) than values obtained in this study.

The endothelial cell loss at the first post-operative week was similar, but slightly higher in this study (4.51\%) to that obtained by Dick B et al in 1995.12 (3.5\%). The mean endothelial cell density on the first postoperative day after phaco was similar to study by Wilczsynski M et al in 2006.13 (2079+/-399 cells $\left./ \mathrm{mm}^{2}\right)$ was similar to this study (2240.92 cells $/ \mathrm{mm}^{2}$ ). However, the endothelial cell loss on first postoperative day was lesser in this study $(3.46 \%)$ than the study by Wilczynski M et al (7.6\%).

There is no significant difference in endothelial cell loss between the phaco group and the SICS group in this study, which is similar to study by Gogate P et al in 2010.11 However, the result by Ganekal S et al in 2014.14 a statistically significant difference between the endothelial cell density was found at week 1 and 6 postoperatively between the SICS and the phaco group. A meta-analysis of randomised controlled trials by Zang JY et al in 2013.15 showed no significant difference between endothelial cell count loss in SICS versus phacoemulsification, which is similar to the result obtained in this study.

\section{Limitations of the Study}

The study was a longitudinal observational study due to time and financial constraints. It would have been better if an age and sex matched double blinded randomised controlled trial was done. In addition, the relation of multiple other factors (Diabetes, pseudo-exfoliation, glaucoma, nuclear sclerosis) to postoperative outcome in both the groups could have been studied if the study was of longer duration and more subjects were included.

\section{CONCLUSION}

There is no statistical significance in the decrease in endothelial cell count or increase in CCT between in SICS and phacoemulsification.

\section{REFERENCES}

1. Teruo Nishida. Cornea. In: Krachmer, Mannis, Holland, editor. Cornea, $2^{\text {nd }}$ ed. Elsevier Mosby: 2005;1:3-17.

2. Khurana AK, Khurana I. Anatomy and physiology of eye. New Delhi: CBS publishers and distributors private ltd. 2006; $2^{\text {nd }}$ ed:22-34.

3. Sobottka Ventura AC, Walti R, Bohnke M. Corneal thickness and endothelial density before and after cataract surgery. Br J Ophthal 2001;85:18-20.

4. Philips C, Laing R, Yee R. Specular microscopy. In: Krachmer, Mannis, Holland, editor. Cornea $2^{\text {nd }}$ ed. Elsevier Mosby: 2005;1:261-80.

5. Goldenberg D, Habot-Wilner Z, Glovinsky Y, et al. Endothelial cells and central corneal thickness after modified sutureless manual small incision cataract surgery. Eur J Ophthalmol 2013;23(5):615-778. Available at URL:http://www.ncbi.nlm.nih.gov/pubmed/23539462.

6. Amon M, Menapace R, Scheidel W. Results of corneal pachymetry after small incision hydrogel lens implantation and sclera step incision poly (methyl methacrylate) lens implantation following phacoemulsification. J Cataract Refract Surg 1991;17(4):466-70. Available at URL: http://www.ncbi.nlm.nih.gov/pubmed/1895223.

7. Amon M, Menapace R, Radax U, et al. Endothelial cell density and corneal pachymetry after no stitch, small incision cataract surgery. Doc Ophthalmol 1992;81(3):3017. Available at URL: http:// www. ncbi.nlm. nih.gov/ pubmed/1483372.

8. Mathew PT, David S, Thomas N. Endothelial cell loss and central corneal thickness in patients with and without diabetes after manual small incision cataract surgery. Cornea 2011;30(4):424-8. Available at

URL: http://www.ncbi.nlm.nih.gov/pubmed/20885307.

9. George R, Rupauliha P, Sripriya AV, et al. Comparison of endothelial cell loss and surgically induced astigmatism following conventional extracapsular cataract surgery, manual small incision surgery and phacoemulsification. Ophthalmic Epidemiol 2005;12(5):293-7. Available at URL: http://www.ncbi.nlm.nih.gov/pubmed/16272048. 
10. Thakur SK, Dan A, Singh M, et al. Endothelial cell loss after small incision cataract surgery. Nepal J Ophthalmol 2011;3(2):177-80. Available at

URL:http://www.ncbi.nlm.nih.gov/pubmed/21876594.

11. Gogate P, Ambardekar P, Kulkarni S, et al. Comparison of endothelial cell loss after cataract surgery: phacoemulsification versus manual small-incision cataract surgery. J Cataract Refract Surgery 2010;36(2):247-53. Available a URL:http://www.ncbi.nlm.nih.gov/pubmed/20152605.

12. Dick B, Khonen T, Jacobi KW. Endothelial cell loss after phacoemulsification and $3 \mathrm{mmvs} 5 \mathrm{~mm}$ corneal tunnel incision. Ophthalmologue 1995;92(4):476-83. Available at URL:http://www.ncbi.nlm.nih.gov/pubmed/7549332.

13. Wilczynski M, Drobniewski I, Synder A, et al. Evaluation of early corneal endothelial cell loss in bimanual microincision cataract surgery (MICS) in comparision with standard phacoemulsification. Eur J Ophthalmol 2006;16(6):798-803. Available at

URL: http://www.ncbi.nlm.nih.gov/pubmed/17191184.
14. Ganekal S, Nagarajappa A. Comparison of morphological and functional endothelial cell changes after cataract surgery: phacoemulsification versus manual small-incision cataract surgery. Middle East Afr J Ophthalmol 2014;21(1):56-60. Available at

URL:http://www.ncbi.nlm.nih.gov/pubmed/24669147.

15. Zang JY, Feng YF, Cai JQ. Phacoemulsification versus manual small-incision cataract surgery for age related cataract: meta-analysis of randomized controlled trials. Clin Experiment Ophthalmol 2013;41(4):379-86. Available at URL: http://www.ncbi.nlm.nih.gov/pubmed/22958062. 